\title{
Rare Intractable Cervicalgia Related to Exaggerated Disc Height Distraction : Report of Two Cases and Literature Review
}

\author{
Man Kyu Choi, M.D., Sung Bum Kim, M.D., Ph.D., ${ }^{2}$ Jun Ho Lee, M.D., Ph.D. ${ }^{2}$ \\ Department of Neurosurgery, Daegu Catholic University Medical Center, College of Medicine, Catholic University of Daegu, Daegu, Korea \\ Department of Neurosurgery, ${ }^{2}$ Kyung Hee University Hospital, Kyung Hee University College of Medicine, Seoul, Korea
}

We present two cases of unexpected postoperative intractable cervicalgia due to over-sized implant insertion during simple anterior cervical decompression and fusion (ACDF) or artificial disc replacement (ADR). These patients experienced severe cervicalgia mostly related to their neck motion even after standard cervical operations. In both cases, the restored disc heights after the operations were prominently greater than the preoperative disc heights. The patients had not responded to any of the conservative treatments, and unloading of these excessively distracted segments through ultimate revision surgery led to dramatic pain relief. This report emphasizes the increase in distractional forces that takes place after a standard ACDF or ADR, as well as the importance of a proper sized implant. It also includes the reviews of other biomechanical or clinical reports dealing with this issue, thereby cautioning the surgeons not to disregard these factors, which might have an adverse effect in patients with cervicalgia even after radiographically successful cervical procedures.

Key Words : Allografts · Total disc replacement · Cervicalgia · Decompression.

\section{INTRODUCTION}

Standard anterior cervical decompression and fusion (ACDF) is regarded as the gold standard for the treatment of cervical radiculopathy and myelopathy ${ }^{6,10,17)}$. One of the important factors affecting the overall outcome is the restoration of the intervertebral disc height, which is achieved via anterior cervical distraction, and placement of an appropriately sized intervertebral graft ${ }^{2,3)}$. However, the decision of the ideal graft height for successful anterior reconstruction of the cervical spine remains controversial, and the selection of an improper- ly sized graft might adversely affect the clinical outcome.

While a large graft may distract the anterior column, thereby indirectly decompressing the neural elements through indirect increase of the foraminal height and unbuckling of the ligamentum flavum ${ }^{1)}$, excessive anterior distraction may decrease the load transmission in the posterior column, thereby subjecting the anterior graft, vertebral bodies, and attached muscular structures (e.g., longus colli) to excessive loads ${ }^{15)}$. Over-distraction could be associated with facet joint injury or subsequent postoperative neck pain ${ }^{8,9)}$, although few studies have reported this problem ${ }^{11)}$.

- Received : June 12, 2017 •Revised : August 16, 2017 •Accepted : August 31, 2017

-Address for reprints : Jun Ho Lee, M.D., Ph.D.

Department of Neurosurgery, Kyung Hee University Hospital, Kyung Hee University College of Medicine, 23 Kyungheedae-ro, Dongdaemun-gu, Seoul 02447, Korea

Tel : +82-2-958-8405, Fax : +82-2-958-8380, E-mail : mo09924@khu.ac.kr

This is an Open Access article distributed under the terms of the Creative Commons Attribution Non-Commercial License (http://creativecommons.org/licenses/by-nc/4.0) which permits unrestricted non-commercial use, distribution, and reproduction in any medium, provided the original work is properly cited. 
In the current report, the authors report on two patients who presented with prolonged cervicalgia after initial ACDF or artificial disc replacement (ADR) using over-sized implants. In both cases, the pain was disregarded as 'neuropathic pain of unknown origin' because the original surgeon considered achievement of radiographic solid fusion and a wellmaintained ADR construct as indicators that the source of pain had been eliminated.

\section{CASE REPORT}

\section{Case 1}

A 43-year-old woman presented with severe occipital neuralgia, headache, and tenderness over the sternocleidomastoid (SCM) muscle, occurring since her first ACDF in April 2009. The original diagnosis was a C5-6 left herniated nucleus pulposus (HNP), which was treated with standard ACDF at

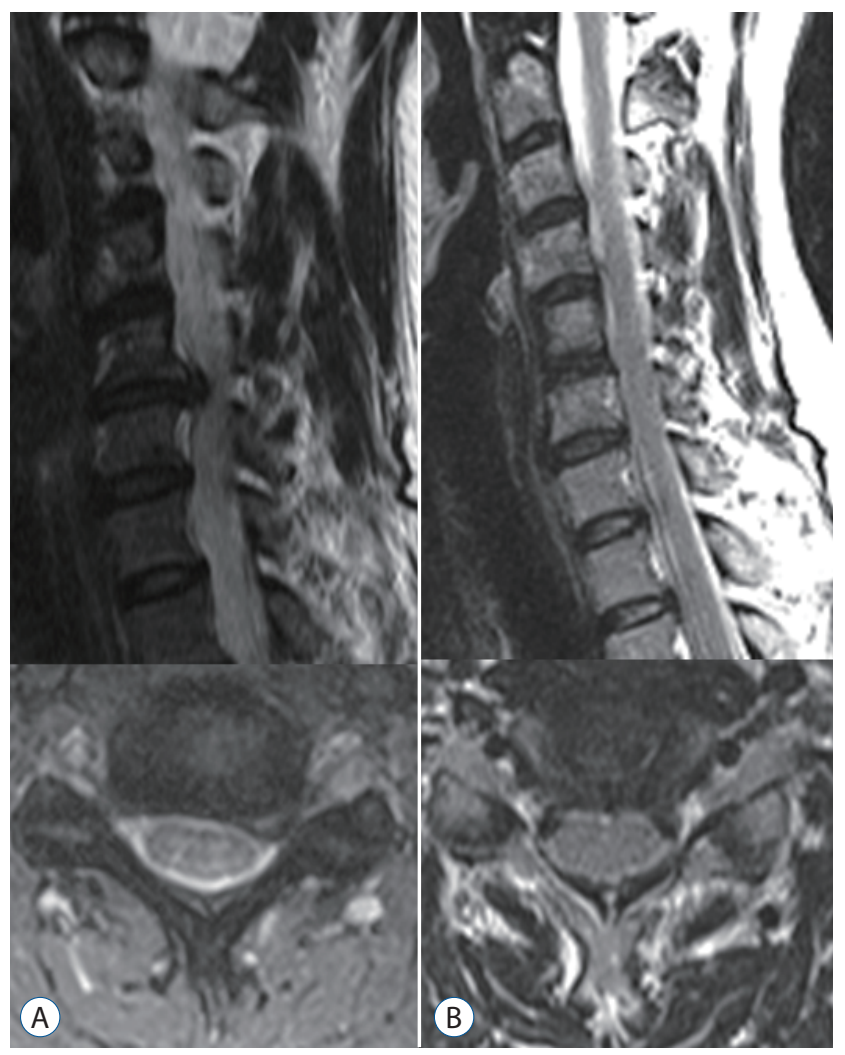

Fig. 1. First operation in case $1:$ anterior cervical decompression and fusion at C5-6. Pre-operative (A) and post-operative (B) T2-weighted magnetic resonance images with definite evidence of good decompression of preoperative herniated intervertebral disc at the left paracentral. the corresponding level by another spine surgeon (Fig. 1). Despite relief of pain in her left arm, she started experiencing severe headache starting from the dorsal portion of the neck to the occiput, even radiating to the vertex of her head, immediately after the operation. Merely disregarded as a common sequela after cervical fusion surgery by the initial surgeon, the condition was conservatively managed with pain killer medication and block therapy over the C5-6 epidural, facet joints, and occipital nerve, which did not result in any conspicuous improvement. Over a span of 5 months after the initial surgery, her symptoms aggravated with concordant development of hand tremor, dorsalgia, and tenderness all over the nuchal and SCM muscles, necessitating multiple visits to neurologists and psychiatrists for treatment of depression and suicidal ideation. Although the symptoms were severe, she fortunately did not show any neurological deficit.

The patient's main complaint was related to the inability to move her neck due to pain provocation especially on flexional motion, suggesting that there was a larger physical load on the anterior column of the cervical spine than there was preoperatively. The final X-ray and computed tomography images showed well fused C5-6 level with cage but her disc height had enlarged from 4.67 preoperatively to $7.36 \mathrm{~mm}$ postoperatively without any subsidence (Fig. 2). The authors decided to

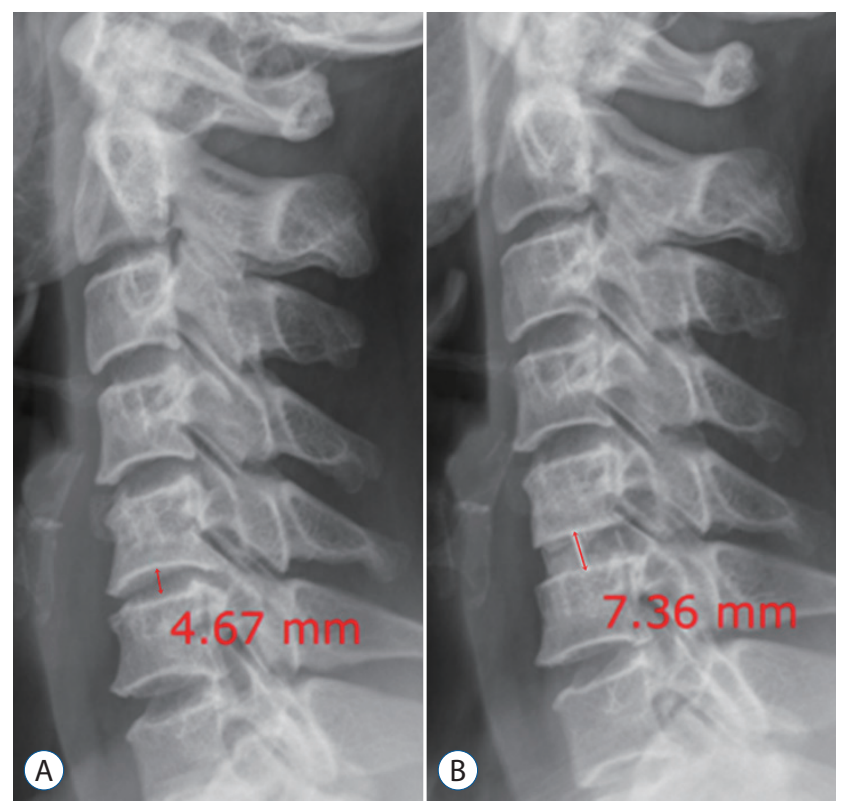

Fig. 2. Pre-operative lateral view of the plain radiograph shows the disc height at C5-6 level to be $4.67 \mathrm{~mm}(\mathrm{~A})$, which overwhelmingly increased to $7.36 \mathrm{~mm}$ (B) after cage insertion and fusion. 
unload this excessively distracted condition through the revision of ADR using a 4.75-mm height device to restore the patient's original disc height. This would provide a more physiologically normal motion, while lessening the concern about the delayed subsidence by the iatrogenic endplate disruption during ADR surgery. The patient experienced complete pain relief within 2-3 days after the surgery. While symptoms like a tingling sensation on both fingertips and a slight headache on the vertex remained, she was satisfied with the result and was discharged on the 10th postoperative day. The postoperative X-ray image showed an appropriately located artificial disc with the disc height reduced to $5.81 \mathrm{~mm}$ (Fig. 3).

\section{Case 2}

A 41-year-old man presented with severe cervicalgia and allodynia in the form of a pricking pain in the forearm. It was originally diagnosed as a C6-7 right HNP, and was treated with ADR at the corresponding level (Fig. 4). He was barely

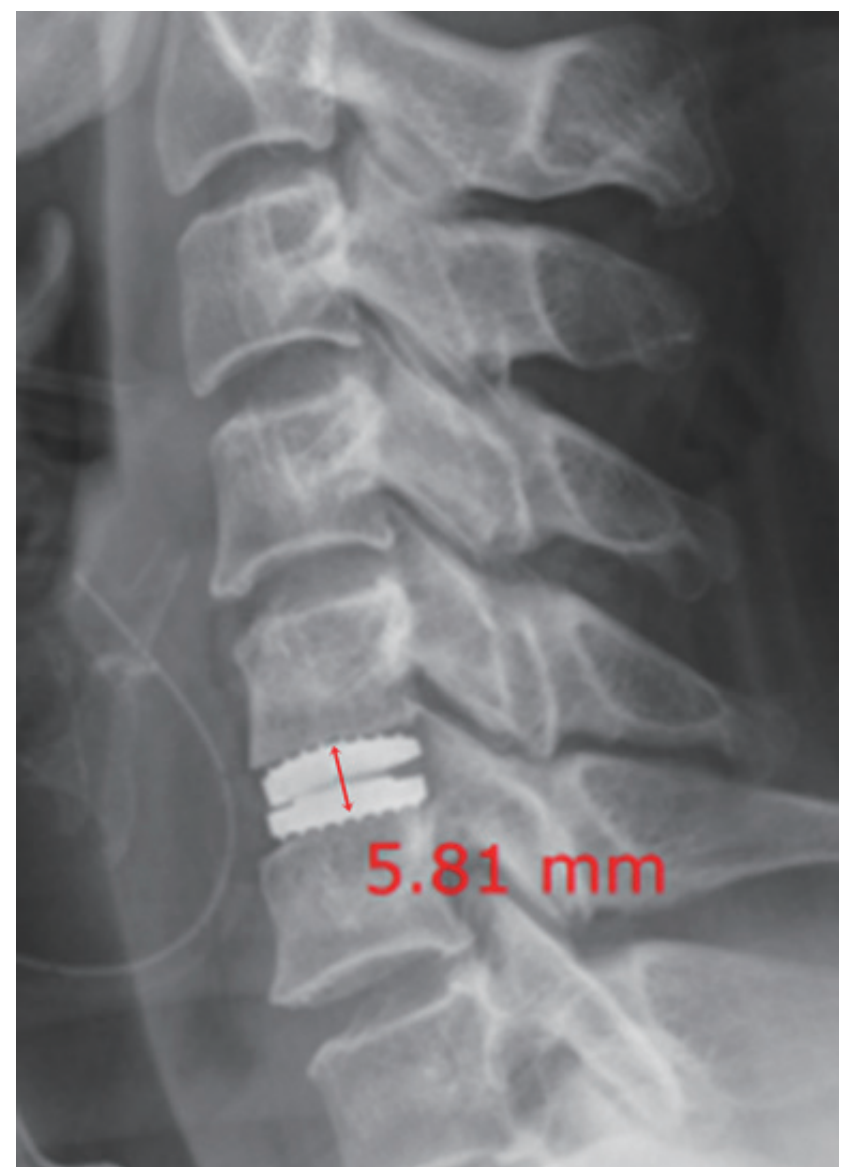

Fig. 3. Post-operative lateral plain radiograph shows a well-inserted artificial disc and a decreased disc height of $5.81 \mathrm{~mm}$. spared from his original right arm radiculopathy for less than two months after the operation. As in case 1, his pain was conservatively managed with pain killer medication and block therapy over the C6-7 right foraminal and facet joints by the original surgeon, which did not result in any conspicuous improvement. Preoperative radiologic imaging led to a suspicion of another spondylosis at the C5-6 level, consequently leading to another ACDF surgery at C5-6 (Fig. 5), instead of a thorough re-inspection at the originally operated level of C6-7. This secondary fusion surgery at the cranial level of C5-6 was non-beneficial and rather harmful for the patient, as it led to re-emergence of the previous non-dermatomal pain in the right forearm as well as cervicalgia that could not be controlled in spite of various symptomatic treatments. Disregarded as a common sequela after cervical surgery by the initial surgeon, as in the previous case, his condition was conservatively managed before referral to the authors.

Follow up X-ray imaging showed relatively well-maintained

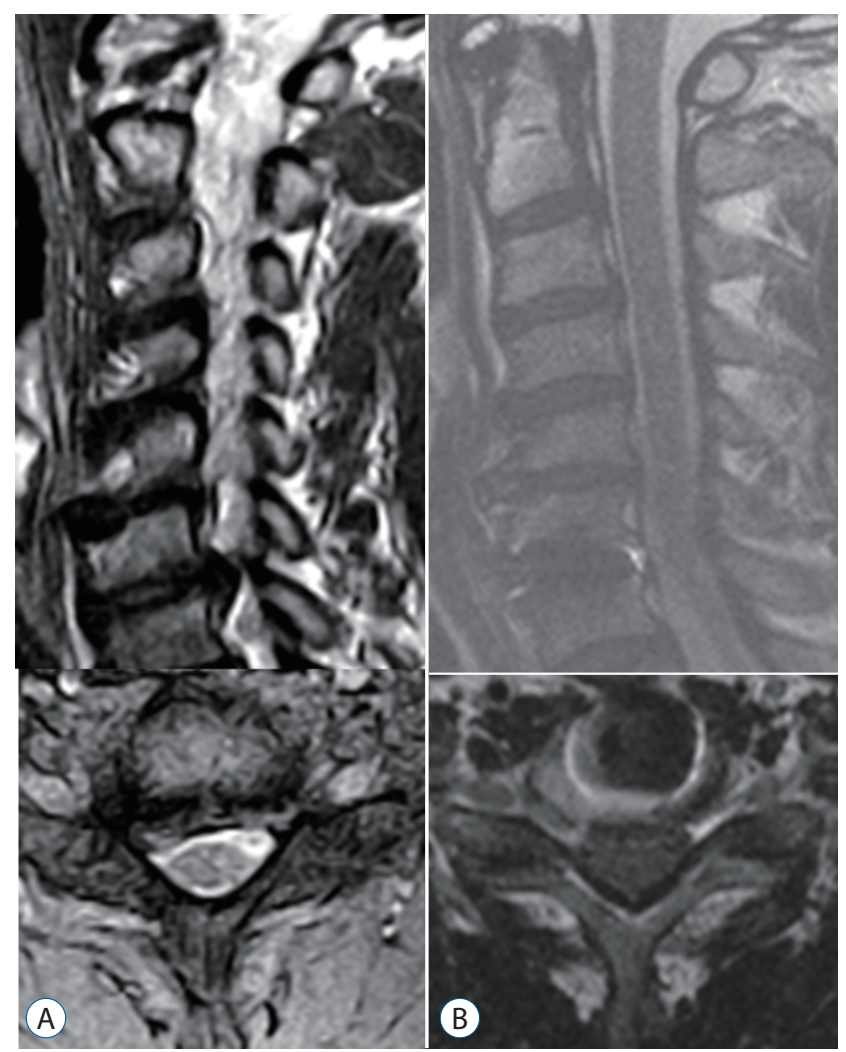

Fig. 4. First operation in case 2 : artificial disc replacement at C6-7. Preoperative (A) and post-operative (B) T2-weighted magnetic resonance images with definite evidence of good decompression of preoperative herniated intervertebral disc at the right paracentral. 
constructs as a result of the two previous operations at levels C5-6 as well as C6-7, except for the fact that the original disc height of $5.51 \mathrm{~mm}$ had increased to $7.72 \mathrm{~mm}$ without any subsidence after the insertion of a $6.25-\mathrm{mm}$ artificial disc implant at the C6-7 level during the initial surgery (Fig. 6). Based on their experience from case 1 , the authors performed a revision cervical arthroplasty only at the C6-7 level to unload this excessively distracted condition using a 5.25-mm height device without hesitation or any manipulation of the upper fused segment (C5-6).

This reduction in the disc height by $1.5 \mathrm{~mm}$ through revision ADR led to considerable pain relief for the patient, although he had to be managed with opioids for up to a year postoperatively due to residual abnormal sensitization in the original right forearm as well as persistent wound pain due to multiple revision surgeries. However, the final X-ray image showed an appropriately located artificial disc with the disc

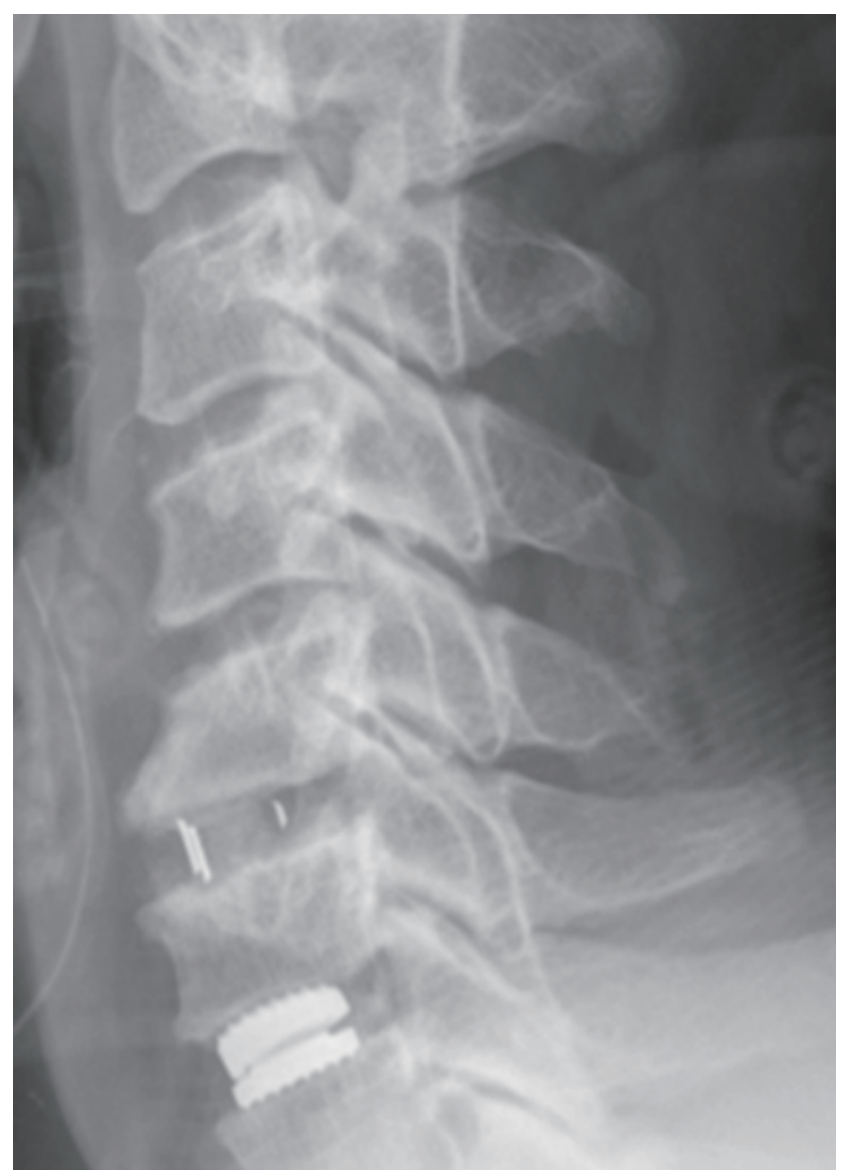

Fig. 5. Second operation in case 2 : anterior cervical decompression and fusion at $\mathrm{C5}-6$. Post-operative lateral pain radiograph shows a wellinserted cage at C5-6. height reduced to $6.29 \mathrm{~mm}$ (Fig. 7) with concomitant clinical improvements.

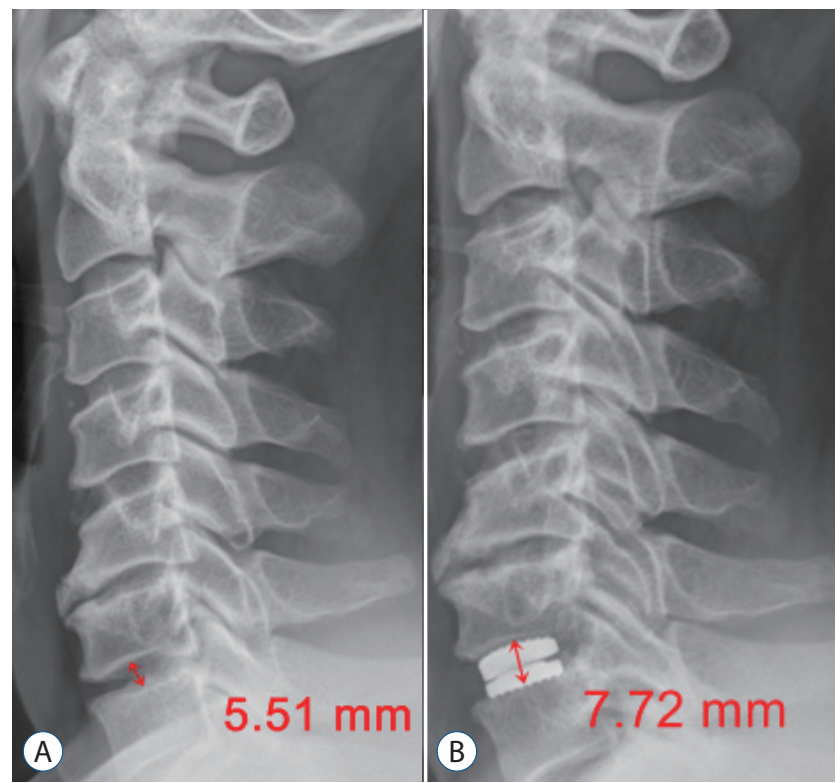

Fig. 6. Pre-operative lateral view of the plain radiograph shows the disc height at C6-7 level to be $5.51 \mathrm{~mm}(A)$, which overwhelmingly increased to $7.72 \mathrm{~mm}(\mathrm{~B})$ after artificial disc insertion.

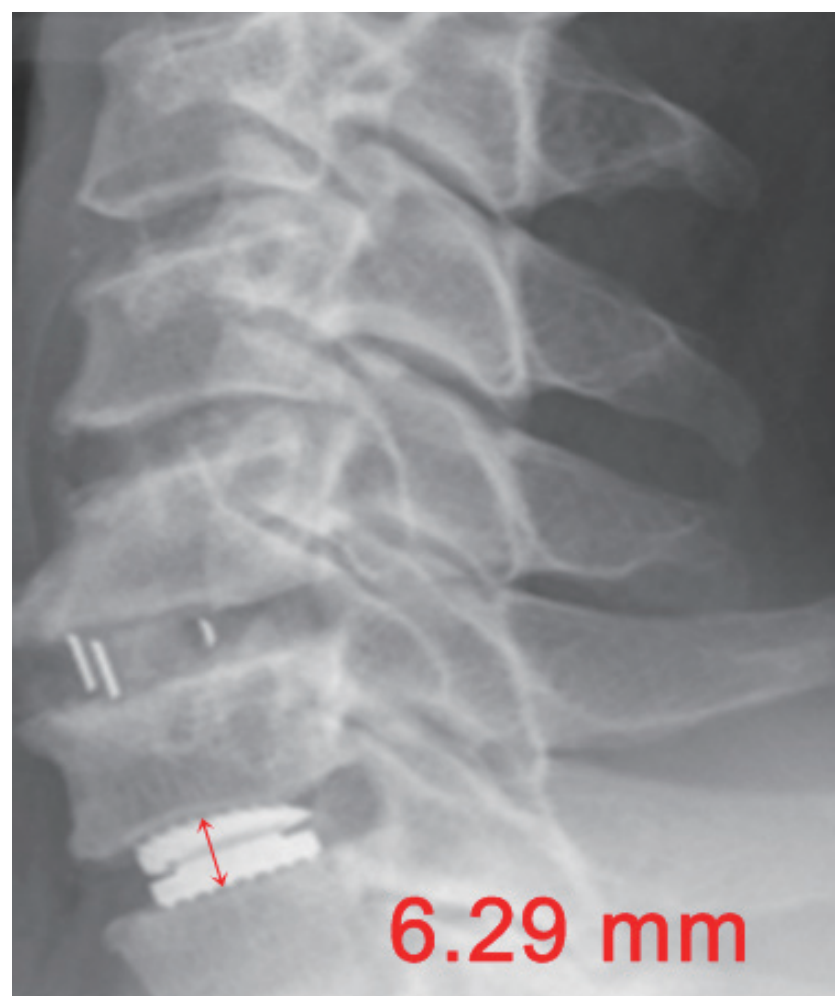

Fig. 7. Post-operative lateral plain radiograph shows well inserted artificial disc and change of disc height from $7.72 \mathrm{~mm}$ to $6.29 \mathrm{~mm}$. 


\section{DISCUSSION}

Although ACDF has become a well-established surgical technique, it is associated with some commonly reported postoperative complications such as graft collapse, non-union, and adjacent segment degeneration ${ }^{7,12,13}$. However, once rigid fusion through ACDF has been achieved, as corroborated by various radiological examinations, and fusion-related complications are absent, there would be not many debates among the spine surgeons upon the idea that the original pain sources have been eliminated and the residual symptom might be related to the elongated nerve root or distracted facet joint due to the restoration of the disc height by the cage insertion.

In contrast to the commonly held view based mainly on these theoretical considerations, in the cases described here, the patients experienced worsening of cervicalgia in spite of achieving solid fusion and a well-maintained ADR construct. Moreover, these symptoms were not relieved even upon elimination of the other possible sources of pain, such as elongated nerve root or distracted facet joint. Upon observing the patients carefully over the course of several months before arriving at the decision of performing revision surgery, the authors noted that the patients were unable to tolerate the limitation on neck movement due to pain provocation, especially during flexion. Therefore, the main hypothesis and rationale underlying the decision of revision surgery was that the patient cannot tolerate the elongated state itself' with excessive disc height distraction.

Typically, grafts during the ACDF procedures are sized by interference fit at the time of surgery or based on preoperative radiographic templating, and any excessive anterior distraction may proportionally decrease posterior column load transmission, thereby subjecting the anterior graft and vertebral bodies to excessive loads ${ }^{15,16)}$. Accordingly, with larger grafts, cervical muscular tone would likely increase in both distractive and compressive forces, and this increased postoperative muscular compressive load would be increasingly transmitted anteriorly through the graft $\mathrm{f}^{15}$. However, it is common for surgeons to be more interested in attaining solid fusion with a firmly fitted graft, neglecting the dynamic factors such as the effect on the cervical musculature and neck motion of the excessive distractive forces required for the insertion of an enlarged cage or its maintenance after fusion.

It is difficult to obviously delineate a specific boundary for an optimized disc height restoration using an ideally sized graft during ACDF or ADR. Actually, there is a paucity of literature addressing this issue since most of these procedures are routinely performed by an arbitrary selection of graft height based on the preoperative radiographic data or on the intraoperative redundancy created after decompression. Chang et al. ${ }^{5)}$ have reported about the relationship between the increased intervertebral disc height and development of postoperative axial neck pain after anterior cervical fusion based on the outcomes from their 155 patient series. Through their average increase of disc height by $2.62 \mathrm{~mm}, 55$ patients (35.4\%) of their series experienced initial posterior neck pain after ACDF. Although they have concluded that there is no significant relationship was observed between the radiological evaluation results regarding the increase in the intervertebral space and clinical findings since most of these neck pain improved after operation and were relieved during the follow-up period, still 21 patients have suffered from persistent axial neck pain refractory to various conservative treatments even up to a year after initial surgery. Another report from Ha et al. ${ }^{9}$ has attributed the exaggerated intraoperative vertebral distraction to the development of transient postoperative axial neck pain by measuring the maximum torque applied on the inserted retractor. Among their 24 consecutive series treated with single level ACDF, either applied with high- $(>6 \mathrm{kgf} \cdot \mathrm{cm})$ or low-torque $(<6 \mathrm{kgf} \cdot \mathrm{cm})$ distractive force before insertion of graft, they reported that only the high-torque group have featured with the immediate postoperative neck pain development. However, all of these experiences of pain were transient not lasting more than 5 days and they could not draw any conclusion regarding the difference of disc height increase in number (average increase of $2.1 \mathrm{~mm}$ ) between the low torque group and the high torque group nor significant relationships among the intervertebral disc height, visual analogue scales, neck disability index scores and torque.

Additionally, several studies have been conducted to evaluate the appropriate graft height in anterior cervical surgery. An et al. ${ }^{1 .}$ performed a cadaver radiographic study and determined that using discs with a preoperative height between 3.5 and $6 \mathrm{~mm}$, the graft height would be elongated by $2 \mathrm{~mm}$ postoperatively. Brower et al. ${ }^{4)}$ retrospectively reviewed ACDF data for 59 patients and found a trend toward nonunion when the preoperative disc height was distracted by more than $4 \mathrm{~mm}$. One study used a finite-element model for evaluating the op- 
timal graft size ${ }^{14)}$. In contrast, there are other reports describing that the preoperative disc height was not an accurate predictor of graft loads in ex vivo model experiments ${ }^{16)}$.

Most of surgeons would simply regard that an overdistraction by inserting an excessive graft material is generally considered to yield postoperative neck pain by inducing a concomitant distraction on the posterior facet joint or spasm of the posterior neck muscle. However, as there has been no previous study defining the relationship between graft size and postoperative axial neck pain conducted, the underlying mechanism of posterior neck pain has not been fully elucidated. Simply other than muscle spasm or the excessive distraction of the facet joint, the instability of the vertebral segment can also lead to posterior neck pain. Olsewski et al. ${ }^{15)}$ have assumed a hypothesis that the appropriate amount of cervical distraction that might affect clinical outcome has not been well defined in the literature and performed a biomechanical analysis using a Smith-Robinson type cervical spine model. Forces across the posterior elements and graft site were measured, during the flexion loading, and compared as the disc space was distracted. Their curious finding was that the ratio of posterior element load to the graft load with increasing disc space distraction significantly decreased due to the significant decrease of posterior element load after the same distraction (from $46.1 \pm 22.0$ to $18.7 \pm 9.7 \mathrm{~N} / \mathrm{Nm}$ ). These findings were more profoundly significant during the spondylotic specimens (original disc height of 4-5 mm) distractions in excess of 3.0 $\mathrm{mm}$ from preoperative height, which might help explaining a limit of effective disc space distraction. Therefore, simply regarding the posterior element including facet joint as a source for postoperative axial neck pain after over distraction (like more than $3 \mathrm{~mm}$ ) would not be proper and prudentially consider the unimaginable painful load that has been transferred over the inserted, but still unstable, graft.

To sum up, the main learning from these two cases that the authors want to reinforce is not that neck pain can be caused by distracted anatomical structures, but the fact that a solidly fused, improper sized cage can place excessive pressure on the cervical musculature, resulting in restriction of neck motion. This indicates that retaining the original physique as well as disc height is sometimes more beneficial for the patient, instead of reconstruction or reduction to achieve normalcy.

\section{CONCLUSION}

The ideal graft height for successful anterior reconstruction of the cervical spine remains unknown and measurements of the preoperative disc height may not be useful predictors of subsequent graft forces. The increased distraction force required to insert and maintain these improper sized grafts results in increased stress and pressure both on the graft and on the cervical neck musculature, leading to intractable cervicalgia even after solid fusion. Surgeons should pay careful attention to these dynamic factors and should not disregard the pain as neuropathic or idiopathic by relying on the verified solid fusion.

\section{CONFLICTS OF INTEREST}

No potential conflict of interest relevant to this article was reported.

\section{INFORMED CONSENT}

Informed consent was obtained from all individual participants included in this study

\section{References}

1. An HS, Evanich CJ, Nowicki BH, Haughton VM : Ideal thickness of smith-robinson graft for anterior cervical fusion. A cadaveric study with computed tomographic correlation. Spine (Phila Pa 1976) 18 : 20432047, 1993

2. Aryan HE, Newman CB, Lu DC, Hu SS, Tay BK, Bradford DS, et al. : Relaxation of forces needed to distract cervical vertebrae after discectomy: A biomechanical study. J Spinal Disord Tech 22 : 100-104, 2009

3. Brodke DS, Zdeblick TA : Modified smith-robinson procedure for anterior cervical discectomy and fusion. Spine (Phila Pa 1976) 17(10 Suppl) : S427-S430, 1992

4. Brower RS, Herkowitz, HN, Kurz L : Effect of distraction on union rate of smith-robinson type anterior cervical discectomy and fusion. Proceedings of the 20th Annual Meeting of the Cervical Spine Research Society; 1992 Dec; Palm Dessert, CA

5. Chang H, Baek DH, Choi BW : The relationship between increased intervertebral disc height and development of postoperative axial neck pain after anterior cervical fusion. J Korean Neurosurg Soc 55 : 343-347, 
2014

6. Choi MK, Kim SB, Park CK, Lee SH, Jo DJ : Relation of deep paraspinal muscles' cross-sectional area of the cervical spine and bone union in anterior cervical decompression and fusion: a retrospective study. World Neurosurg 96 : 91-100, 2016

7. Fountas KN, Kapsalaki EZ, Nikolakakos LG, Smisson HF, Johnston KW, Grigorian AA, et al. : Anterior cervical discectomy and fusion associated complications. Spine (Phila Pa 1976) 32 : 2310-2317, 2007

8. Goffin J, Plets C, Van den Bergh R : Anterior cervical fusion and osteosynthetic stabilization according to caspar: A prospective study of 41 patients with fractures and/or dislocations of the cervical spine. Neurosurgery $25: 865-871,1989$

9. Ha SM, Kim JH, Oh SH, Song JH, Kim HI, Shin DA : Vertebral distraction during anterior cervical discectomy and fusion causes postoperative neck pain. J Korean Neurosurg Soc 53 : 288-292, 2013

10. Kaiser MG, Haid RW Jr, Subach BR, Barnes B, Rodts GE Jr : Anterior cervical plating enhances arthrodesis after discectomy and fusion with cortical allograft. Neurosurgery 50 : 229-236; discussion 236-238, 2002

11. Kwon B, Kim DH, Marvin A, Jenis LG : Outcomes following anterior cervical discectomy and fusion: the role of interbody disc height, angula- tion, and spinous process distance. J Spinal Disord Tech 18 : 304308, 2005

12. Miller LE, Block JE : Safety and effectiveness of bone allografts in anterior cervical discectomy and fusion surgery. Spine (Phila Pa 1976) 36 : 2045-2050, 2011

13. Nasser R, Yadla S, Maltenfort MG, Harrop JS, Anderson DG, Vaccaro $A R$, et al. : Complications in spine surgery. J Neurosurg Spine 13 : 144-157, 2010

14. Natarajan RN, Chen BH, An HS, Andersson GB : Anterior cervical fusion: a finite element model study on motion segment stability including the effect of osteoporosis. Spine (Phila Pa 1976) 25 : 955-961, 2000

15. Olsewski JM, Garvey TA, Schendel MJ : Biomechanical analysis of facet and graft loading in a smith-robinson type cervical spine model. Spine (Phila Pa 1976) 19 : 2540-2544, 1994

16. Truumees E, Demetropoulos CK, Yang KH, Herkowitz HN : Effects of disc height and distractive forces on graft compression in an anterior cervical discectomy model. Spine (Phila Pa 1976) 27 : 2441-2445, 2002

17. Zhou J, Xia Q, Dong J, Li X, Zhou X, Fang T, et al. : Comparison of stand-alone polyetheretherketone cages and iliac crest autografts for the treatment of cervical degenerative disc diseases. Acta Neurochir (Wien) $153: 115-122,2011$ 